Rabinow, Paul. 1991. "Artificiality and Enlightenment: From Sociobiology to Biosociality.” In Incorporations, edited by Jonathan Crary and Sanford Kwinter, 234-52. New York: Zone Books.

Richardson, Sarah S., and Hallam Stevens, eds. 2015. Postgenomics: Perspectives on Biology after the Genome. Durham, NC: Duke University Press.

Rose, Nikolas. 2007. "Molecular Biopolitcs, Somatic Ethics and the Spirit of Biocapital." Social Theory and Health 5:3-29.

Scheper-Hughes, Nancy, and Margaret Lock. 1987. "The Mindful Body: A Prolegomenon to Future Work in Medical Anthropology.” Medical Anthropology Quarterly 1 (1): 6-41.

TallBear, Kim. 2013. Native American DNA: Tribal Belonging and the False Promise of Genetic Science. Minneapolis: University of Minnesota Press.

Taussig, Karen-Sue, Rayna Rapp, and Deborah Heath. 2003. "Flexible Eugenics: Technologies of the Self in the Age of Genetics.” In Genetic Nature/Culture: Anthropology and Science Beyond the TwoCulture Divide, edited by Alan H. Goodman, Deborah Heath, and M. Susan Lindee, 58-76. Berkeley: University of California Press.

Thayer, Zaneta M., and Amy L. Non. 2015. "Anthropology Meets Epigenetics: Current and Future Directions.” American Anthropologist 117 (4): 722-35.
Todd, Zoe. 2018. "The Decolonial Turn 2.0: The Reckoning." anthro $\{$ dendum $\}$, June 15. https://anthrodendum. org/2018/06/15/the-decolonial-turn-2-0-the-reckoning/.

Tsing, Anna. L. 2005. Friction: An Ethnography of Global Connection. Princeton, NJ: Princeton University Press.

Walters, Karina L., Selina A. Mohammed, Teresa Evans-Campbell, Ramona E. Beltrán, David H. Chae, and Bonnie Duran. 2011. "Bodies Don't Just Tell Stories, They Tell Histories.” Du Bois Review: Social Science Research on Race 8 (1): 179-89.

Warin, Megan, Vivienne Moore, Michael Davies, and Stanley Ulijaszek. 2015. "Epigenetics and Obesity: The Reproduction of Habitus through Intracellular and Social Environments.” Body \& Society 22 (4): 1-26.

Wirihana, Rebecca, and Cherryl Smith. 2014. "Historical Trauma, Healing and Well-Being in Māori Communities." MAI Journal 3 (3): 197-210.

Yehuda, Rachel, Nikolaos P. Daskalakis, A. Lehmer, Frank Desarnaud, Heather N. Bader, Iouri Makotkine, Janine D. Flory, Linda M. Bierer, Michael J. Meaney. 2014. "Influences of Maternal and Paternal PTSD on Epigenetic Regulation of the Glucocorticoid Receptor Gene in Holocaust Survivor Offspring." American Journal of Psychiatry 171 (8): 872-80.

\title{
Essay
}

\section{Having Impact: Doing Applied Medical Anthropology in Australia and Malaysia}

\section{Narelle Warren \\ Monash University, Australia \\ Pascale Allotey \\ United Nations University-International Institute for Global Health, Malaysia}

Daniel D. Reidpath

Monash University Malaysia

$\mathrm{T}$ ranslating medical anthropology into practice is increasingly important to ensure that it informs policy and interventions that improve health outcomes. We work in settings where this "knowledge translation" is now an explicit expectation, although how this is borne out differs. For Allotey, who leads a global public health institute, and Reidpath, whose work informs national institutes of health, providing anthropological insights that can enhance, transform, or otherwise influence how health and its interventions are understood and implemented at the policy and community levels is an expected - and integralpart of their roles. For Warren, funding and university environments have their own agendas around research translation and knowledge transfer, both notions that ultimately speak to the need for research to be usable in some way.
These issues speak to a larger debate about the impact and the return on investment of research. Within an applied space, research questions often need to be policy driven and timely. Outcomes are the primary drivers. In higher education institutions, research-funding models often require significant contribution to the discipline and reflect shifting priorities of the government, particularly in the case of public universities.

In late 2015 , the main nationally competitive funding agency for anthropologists, the Australian Research Council, announced its funding priorities under the "National Innovation and Science Agenda" (www.arc.gov.au/nisa). Built into this was - is - the expectation that research should have "impact" and "engagement" in order to access institutional and governmental support. What these terms mean in practice is open to interpretation and, importantly, may differ from the definitions with which we are familiar. After all, isn't an integral part of what we do as medical anthropologists engagement? In undertaking ethnographic research, we engage with literature, governance and policies, power and vested interests, communities, individual participants, and environments. Yet the "National Innovation and Science Agenda," and those like it, are less concerned with these types of engagement, focusing instead on the measurable 
influence of our research outputs. Under this rubric, ideas of impact and engagement must be reinterpreted in light of recent shifts that increasingly shape universities based on corporate and bureaucratic models, in which a concern with metrics is central (Cox 2013; Stelmach and von Wolff 2011). This poses problems for medical anthropologists to which the authors of this essay do not have the answers. Rather, in this essay, we draw upon our own experiences to discuss some challenges that these emerging agendas give rise to for medical anthropology.

\section{MEDICAL ANTHROPOLOGY, WHAT'S THAT? PROVIDING INSIGHTS FROM AN UNFAMILIAR DISCIPLINE}

How - and how well — we can do translational and impactful medical anthropological research is significantly shaped by the regard for and recognition afforded to the discipline at the academic, popular/community, and state levels. In Malaysia, as in Australia, as Long and Baer (2018) note, medical anthropology is a small and somewhat marginalalbeit growing - subdiscipline. Few members of the broader community seem to have an understanding of what medical anthropology is or what insights it can offer (if the number of times we need to provide a definition of the discipline is an indication). This is not limited to the subdiscipline of medical anthropology but may also extend to anthropology more broadly. High school students are not taught anthropology, although they do receive instruction in anthropological concerns (e.g., indigeneity, diversity) as part of their education in social studies or the humanities. For most people, popular media provide their only introduction to the discipline, which is thus understood as something to do with archaeology (perhaps an artifact of the popularity of the Indiana Jones movies) or forensic anthropology (courtesy of the television show Bones). Yet, as Long and Baer (2018) highlight, these reflect a four-fields approach to anthropology that doesn't align with the European-informed sociocultural anthropology taught in Malaysian and Australian universities (see also Manderson and Levine 2018).

Medical anthropology is taught at less than one-quarter of Australian undergraduate universities (and about one-half of those that offer undergraduate anthropology, according to Long and Baer [2018]). Where students do encounter a health- or medically aligned anthropology as undergraduates, this is rarely more substantive than a single partsemester-length module, usually as one of several semesterlong courses. Indeed, most people only encounter medical anthropology at the graduate level. Similar patterns exist in Malaysia, where Allotey and Reidpath are based, although the offerings are fewer given general preference for vocationally focused degrees that lead directly into employment. Five Malaysian universities offer undergraduate anthropology as part of a social sciences or liberal arts degree, and of these, three offer at least one medical anthropology course (data from www.afterschool.my). This contrasts significantly with health sociology, which is more widely offered.
As it is taught, practiced, and communicated in both settings (Australia and Malaysia), medical anthropology is a discipline that is notable because of how often it draws on or aligns with other disciplines (see Long and Baer 2018), most often public health, general practice, psychology, Indigenous studies, or a combination of these.

Educated within the Australian context, like many of our peers, we came to medical anthropology during doctoral training, following undergraduate training in the fields of nursing and midwifery (Allotey) or sociology and psychology (Warren). Yet, since completing our formal training, our own medical anthropological practices have evolved in response to the communities with whom we work and the focus of our work. We have sought to undertake research that can inform public health practices and thus will have an impact (in some way) on the lives of those with whom we work. Allotey and Reidpath (a social epidemiologist) have successfully worked together for over two decades in translating medical anthropology to inform public health theory and interventions. Their comparative work in Australia and Cameroon, for example, employed ethnography to question the core assumptions of the disability-adjusted life year (DALY) and demonstrated that there is no universality in the burden of disease based purely on the health condition (Allotey et al. 2003; Allotey and Reidpath 2007). Below, we reflect on our experiences in order to generate new discussions about how medical anthropology can increase its impact in settings where it is not seen as mainstream.

\section{QUESTIONS OF RELEVANCE: ENGAGING ACROSS DISCIPLINES}

Medical anthropology in both Malaysia and Australia often needs to have a strong public health focus to avoid the "interesting, but so what?" questions from research and practicing public health specialists. Rather than being seen as foundational, medical anthropology is often seen by these more applied practitioners as providing direction and clarity around the implementation of behavior-change recommendations rather than as the driver of new areas for health policy and service planning. While this seems antithetical at the disciplinary level - and we firmly believe that medical anthropological insights are deeply valuable in and of themselves - such an approach is not entirely surprising given the context of medical anthropology training outlined above (also see Long and Baer 2018). At the same time, the popular privileging of science, technology, engineering, and mathematics (STEM) disciplines over the social sciences contributes to the sidelining of medical anthropological research even where its role is central to knowledge generation. For example, Warren's postdoctoral research gave rise to questions about the role of farming and chemicals in the etiology of Parkinson's disease, which she and collaborators from public health and neuroscience then explored through secondary analyses of health insurance data. However, in subsequent media coverage, policy, and support services, only the contribution of public health and the neurosciences was recognized. This example 
highlights how medical anthropologists often work without the recognition of our expertise (especially in contrast to that given to our STEM colleagues), which then impacts our capacity to effect change as a result of research insights.

Related to this, the impact and recognition of the contributions of medical anthropology in Australia and Malaysia have been shaped by narrow understandings of the discipline, what it does methodologically, and what knowledge it can provide. Importantly, our experience has been that public health has limited expectations of what medical anthropology can provide and how the arrived-at insights can be made relevant at the local level. One of the first challenges for medical anthropology in Australia and Malaysia relates to raising broader awareness of the discipline and its contribution at multiple levels among health-care professionals, policymakers, other academic researchers, and the community at large. This, of course, is beyond the reach of any individual anthropologist, but it is an important outreach activity to which we all can contribute.

Public health research - at least in the settings where we work - is often based on the assumption that structural dimensions can be readily separated from one another. Dimensions of gender, culture, social class, and ethnicity are regarded as distinct aspects of experience, which may intersect with one another, yet remain able to be disentangled. This assumption is often brought to bear in quantitative research, in which these dimensions are considered as separate variables that can then be examined in terms of their direct, mediating, or moderating influences - or which can be controlled for (in which attempts are made to reduce the effect of such variables). Indeed, much work on the Social Determinants of Health (Dahlgren and Whitehead 1991) relies on the assumption that these dimensions, or variables, can be considered individually. Indeed, this capacity to operationalize variables in a way that can be used to structure a research protocol is a hallmark of much public health research.

As anthropologists, however, we are cognizant of the impossibility of the task of trying to view one social determinant as independent from any others because, through training and research, we know these structural factors overlap and intersect, and thus cannot be easily pulled apart (Manderson and Warren 2016). Indeed, medical anthropology starts with the assumption that multiple structural factors intersect in multiple ways that can profoundly shape who experiences what conditions and how that condition might progress. These insights are of direct relevance for public health practice as well as for clinical services. Our current research on stroke in rural Malaysia, for example, documents how ethnicity, gender, rurality, and access to economic resources intersect to promote or hinder longterm stroke recovery (Mairami et al., forthcoming). Such insights are important given that stroke is the third most significant contributor to mortality in Malaysia.

The resultant tension between the bluntness of public health categories and the medical anthropological concern with the intersections of these structural factors in context should give rise to particular considerations when designing public health research - and extends to the dissemination and translation of our insights. This tension is, however, predominantly felt by the anthropologist in the research team precisely because our training asks us to examine nuance and contingency, whereas public health does not (or at least not so much). For example, the merging and consequent inseparability of religion and ethnicity in Malaysia places particular boundaries on research: the association between Islam and Malay ethnicity is enshrined in the constitution, for example, which means that the variability in people's expressions of identity is instead incorporated together into a single "ethnic" category. Crude ethnic categories are also used in Australian research, whereby the multiplicities of ethnicity are often distilled into a single ethnic category. The smoothing out, or reduction, of complexity in common variables presents a challenge to public health researchers in designing research protocols that capture diversity yet can still be perceived as useful by governments.

Throughout our careers, we have been engaged in teams to provide insights into "what it means to live with $\mathrm{X}$ condition" rather than provide a deeper sociocultural analysis of those same bodily states. Yet it is precisely at that deeperlevel analysis where anthropological insights are especially relevant. Allotey's work on verbal autopsy offers evidence of this. Due to religious and/or cultural practices (Allotey et al. 2015), it is not always possible to determine medically a person's cause of death, yet it is important for public health, epidemiology, and demographic registries that this information is recorded. Verbal autopsy involves interviewing people close to the dead person to obtain systematic information on the cause of death (Garenne and Fauveau 2006). Anthropology provides guidance into locally and culturally appropriate ways to collect this information (Aborigo et al. 2013), which may occur during periods of grief. Verbal autopsies draw upon anthropological methods to engage community members and develop understandings of a cause of death in order to identify the major health problems occurring in particular communities and can thus aid in the development and evaluation of health programs (Garenne and Fauveau 2006). These are especially important where cultural or religious practices or environmental conditions necessitate interment as soon as possible, which means that autopsy — and, thus, the establishment of a definitive cause of death - cannot occur. This is the case in most Muslim countries, including Malaysia.

As members of interdisciplinary research teams, medical anthropologists can provide important insights regarding how different structural factors may impact health through the development of research protocols and methodologies that enable a consideration of the nuances that might shape experience, such as in the case of rurality or indigeneity. Ethnography - through employing sound and rigorous anthropological method and analysis - has a valuable place in public health research, engaging with these dimensions and examining their meanings (see Colvin 2018). 


\section{ENGAGING THE STATE}

Medical anthropology, as it is practiced in various settings, is profoundly shaped by state policies and local social practices (see Manderson and Levine 2018), both in terms of the substantive area of inquiry and in how we communicate our research findings. As the essays from the September 2018 World Anthropologies section of American Anthropologist illustrate, good medical anthropology, regardless of where it is undertaken, necessarily considers the multiple layers of context that impact the communities in which we work. Both Malaysia and Australia provide universal health care through a mix of publicly and privately funded services. At the same time, health is delivered through multiple levels of government, mostly at the nation-state and federated-state levels. Adding further complexity, consumer-facing organizations can play an important role in advocating to government and providing direct support. All of these layers influence the substantive research topic but also provide opportunities for impact. In our stroke research in Malaysia, having an understanding of the relevant health-care policies-including those on emergency medicine, rehabilitation provision, aged care, and medications - and clinical practice guidelines also provides a starting point for translation into practice. Understanding the policy environment gives legitimacy to our insights. It not only demonstrates an engagement with the local context but also reflects a recognition of some of the challenges to putting academic insights into practice.

Beyond this, there remains a challenge for medical anthropologists to consider how we can then make these concepts useful. A strong divide between quantitative and qualitative research in both Australia and Malaysia persists, which often means that medical anthropology is largely seen as a way of supporting quantitative data (as discussed above). This gives rise to new challenges in undertaking medical anthropology research with impact in terms of trying to explain to government what ethnographic data collection is (in comparison with basic interview-based qualitative research), what it offers to a project, or how people's everyday experiences provide valuable sites for knowledge production. Importantly, medical anthropology highlights the value in examining the intuitive or internal factors that are taken-forgranted aspects of the everyday (which are assumed to be outside of knowledge or outside of interrogation). Because of a concern at the state level with innovation, particularly in the context of an increasingly competitive global research market, it can be difficult to explain - given research environments concerned with impact and its metrics - that the everyday aspects of experience are understandable and knowable units. This is a challenge that medical anthropology continues to grapple with in many parts of the world.

We hold out hope for medical anthropology and its translation. Global agendas, most notably the Sustainable Development Goals, task anthropologists with critically engaging with the causes of inequality across settings, regardless of whether they conduct research "at home" or elsewhere. This provides opportunities for anthropologists to contribute insights into how such inequities might be best addressed, as evidenced through the provocative "De-Provincializing Development" series on the American Anthropologist website (see Brunson and Mulligan 2017). This effort requires medical anthropological understanding into the foundations of health inequities, particularly in terms of who can access and realize the right to health. There remains considerable scope for medical anthropology to understand not only why some people get left behind in achieving good health and how we can assure that "no one is left behind" but also how government policies can be translated to realize such aspirations.

\section{REFERENCES CITED}

Aborigo, Raymond A., Pascale Allotey, Paulina Tindana, Daniel Azongo, and Cornelius Debpuur. 2013. "Cultural Imperatives and the Ethics of Verbal Autopsies in Rural Ghana." Global Health Action 6:1. https://doi.org/10.3402/gha.v6i0.18570.

Allotey, Pascale, Daniel D. Reidpath, Aka Kouame, and Robert Cummins. 2003. "The DALY, Context and the Determinants of the Severity of Disease: An Exploratory Comparison of Paraplegia in Australia and Cameroon.” Social Science and Medicine 57 (5): 949-58.

Allotey, Pascale, and Daniel D. Reidpath. 2007. "Epilepsy, Culture, Identity and Well-Being: A Study of the Social, Cultural and Environmental Context of Epilepsy in Cameroon.” Journal of Health Psychology 12 (3): 431-43.

Allotey, Pascale A., Daniel D. Reidpath, Natalie C. Evans, Nirmala Devarajan, Kanason Rajagobal, Ruhaida Bachok, Kridaraan Komahan, and the SEACO team. 2015. "Let's Talk about Death: Data Collection for Verbal Autopsies in a Demographic and Health Surveillance Site in Malaysia.” Global Health Action 8:1. https://doi.org/10.3402/gha.v8.28219.

Brunson, Emily K., and Jessica Mulligan. 2017. "Falling Further Behind on Health.” American Anthropologist website, July 11. http:/ / www.americananthropologist.org/2017/07/11/fallingfurther-behind-on-health/.

Colvin, Christopher J. 2018. "South African Medical Anthropology in the Wake of HIV.” American Anthropologist 120 (3). Forthcoming.

Cox, Ronald W. 2013. "The Corporatization of Higher Education." Class, Race and Corporate Power 1 (1): 8. https://doi.org/10. 25148/CRCP.1.1.6092151.

Dahlgren, Goran, and Margaret Whitehead. 1991. Policies and Strategies to Promote Social Equity in Health. Stockholm: Institute for Future Studies.

Garenne, Michel, and Vincent Fauveau. 2006. "Potential and Limits of Verbal Autopsies.” Bulletin of the World Health Organization 84 (3): 161-256.

Long, Debbi, and Hans Baer. 2018. "Health Anthropology in Australia." American Anthropologist 120 (3).

Mairami, Fatima, Narelle Warren, Pascale Allotey, Jun Sin Mak, and Daniel D. Reidpath. Forthcoming. "Documenting the Impact of Stroke in a Middle-Income Country: A Malaysian Case Study.” Disability and Rehabilitation.

Manderson, Lenore, and Narelle Warren. 2016. "Just One Thing after Another': Recursive Cascades and Chronic Conditions." Medical Anthropology Quarterly 30 (4): 479-97. 
Manderson, Lenore, and Susan Levine. 2018. "Southward Focused: Medical Anthropology in South Africa." American Anthropologist 120 (3).
Stelmach, Bonnie L., and Stuart D. von Wolff. 2011. "A Challenge to Metrics as Evidence of Scholarity." European Educational Research Journal 10 (1): 64-82.

\section{Commentary \\ The Relevance of Medical Anthropologies' Multiplicities: Interdisciplinarity, Modes of Perception, and Multiple Sovereignties}

\section{Emily Metzner}

University of Illinois at Urbana-Champaign, USA

$\mathrm{T}$ he four essays by medical anthropologists in this section invite me to reflect from several positions. As the World Anthropologies section's editorial assistant and an occasional guest editor (including, with Narelle Warren, of this content and the Special Section on Medical Anthropology in the September 2018 issue of American Anthropologist that precedes it), I have been deeply engaged with all of the section's content since 2015, learning more with each issue about the complexities of the world anthropology/ies movement, its stakes, and many proponents and critics. Some have raised important concerns about a tendency to carve up anthropology in line with the borders of nations, continents, regions, or areas. Nevertheless, many (though not all) of the contributors to the World Anthropologies section write about anthropology as the discipline is practiced within political borders with their problematic, violent, and colonialist geopolitical histories.

As the essays by Warren, by Allotey and Reidpath, and by Addison, Taylor-Alexander, and Battles in this section make clear, and as many others have in different ways before, exploring the ways national or international policies, history, and political economy shape the discipline's priorities, possibilities, and limitations is a worthwhile endeavor - in this case not just for the sake of understanding the discipline in context but also for medical (or other) anthropologists who want to make an impact on such policies. Kowal and Warin's essay about the complexities of epigenetics and its reception, and the importance of anthropological study of epigenetics as the science develops, offers us another way of approaching world anthropologies - thematically, that is. The World Anthropologies section has often taken a theme or two as its focus. Examples include cultural heritage management (March 2017), genomics and indigeneity (June 2018), forensic anthropology (December 2016), nationalism (September 2017), tourism anthropology (December 2017), and, of course, medical anthropology (September 2018 and this issue). Yet, as Kowal and Warin's essay also demonstrates, although thematically focused, each contribution still provides a "view from somewhere."
One thing that strikes me about this December 2018 World Anthropologies section is its decidedly Anglophone bent, with an unusual number of contributors writing from the United States, like me and Heather Howard. While this may fall short of the section's goals around de-centering anthropological knowledge production, I think the inclusion of Howard's essay here makes another vital intervention into the world anthropologies project. Howard's essay offers a reminder of the multiple sovereignties beyond or within borders that do already shape anthropological praxis and might ideally do so even more.

The juxtaposition of the two essays here spurs me to wonder if Kowal and Warin provide an example of the kind of "two-eyed seeing" Howard advocates. Although anthropologists do much more than (and do not need to) see, I would suggest that Kowal and Warin's essay is a good show of the kind of multidisciplinary critical examination, with consideration of historical and structural factors, that Howard seems to model. But it would indeed be interesting to know what the authors think, and what Indigenous scholars think, about this question.

That said, these essays also prompt me to reflect on my work as an anthropologist studying addiction and ambivalent, mercurial approaches to its treatment in US-based, metropolitan drug treatment courts. My work is informed by my previous job as a harm reduction practitioner, doling out new syringes and other tools to help mitigate the risks of violence and infection that attend severely criminalized drug use in marginalized communities in the Bronx, East Harlem, and Washington Heights in New York City. I see similarities to my own research into drug courts in Howard's essay. The harm reduction approach at the organizations I worked for grew out of and was very much a part of radical movements of health sovereignty (carried out by the Black Panthers and the Young Lords, for example) that have taken place in the Bronx and Harlem - what historian Samuel K. Roberts (2016) has called harm reduction of color (HROC) and radical recovery. Indeed, this activism asserted sovereignty in the face of neglect and abuse by the state and did so primarily around issues of health and basic care. Somewhat like Howard, I find in my work that a critical medical anthropology perspective is a good start but not 